\title{
A Randomized Trial to Reduce the Prevalence of Depression and Self-Harm Behavior in Older Primary Care Patients
}

Osvaldo P. Almeida, MD, PbD,

FRANZCP ${ }^{1-3}$

Jane Pirkis, $B S c, P b D^{4}$

Ngaire Kerse, $M B, C b B, P b D$,

FRNZCGP

Moira Sim, MB, FRACGP

Leon Flicker, MBBS, PbD, FRACP $2,7,8$

Jobn Snowdon, MD, MPbil,

FRCPsych ${ }^{9}$

Brian Draper, MD, MBBS,

FRANZCP ${ }^{10}$

Gerard Byrne, MBBS, PbD,

FRANZCP ${ }^{11}$

Robert Goldney, MBBS, MD,

FRANZCP'12

Nicola T. Lautenschlager, MBBS, $M D^{1,2,13}$

Nigel Stocks, DipPH, MD, FRACGP ${ }^{14}$

Helman Alfonso, MD, MHGen, $\mathrm{PbD}^{1,2}$

Jon J. Pfaff, $P b D^{1,2}$

Conflicts of interest: none reported.

\begin{abstract}
PURPOSE We wanted to determine whether an educational intervention targeting general practitioners reduces the 2-year prevalence of depression and self-harm behavior among their older patients.

METHODS Our study was a cluster randomized controlled trial conducted between July 2005 and June 2008. We recruited 373 Australian general practitioners and 21,762 of their patients aged 60 years or older. The intervention consisted of a practice audit with personalized automated audit feedback, printed educational material, and 6 monthly educational newsletters delivered over a period of 2 years. Control physicians completed a practice audit but did not receive individualized feedback. They also received 6 monthly newsletters describing the progress of the study, but they were not offered access to the educational material about screening, diagnosis and management of depression, and suicide behavior in later life. The primary outcome was a composite measure of clinically significant depression (Patient Health Questionnaire score $\geq 10$ ) or self-harm behavior (suicide thoughts or attempt during the previous 12 months). Information about the outcomes of interest was collected at the baseline assessment and again after 12 and 24 months. We used logistic regression models to estimate the effect of the intervention in a complete case analysis and intention-to-treat analysis by imputed chain equations (primary analysis).
\end{abstract}

RESULTS Older adults treated by general practitioners assigned to the intervention experienced a $10 \%(95 \% \mathrm{Cl}, 3 \%-17 \%)$ reduction in the odds of depression or self-harm behavior during follow-up compared with older adults treated by control physicians. Post hoc analyses showed that the relative effect of the intervention on depression was not significant $(\mathrm{OR}=0.93 ; 95 \% \mathrm{Cl}, 0.83$ 1.03), but its impact on self-harm behavior over 24 months was (OR $=0.80 ; 95 \%$ $\mathrm{Cl}, 0.68-0.94)$. The beneficial effect of the intervention was primarily due to the relative reduction of self-harm behavior among older adults who did not report symptoms at baseline. The intervention had no obvious effect in reducing the 24-month prevalence of depression or self-harm behavior in older adults who had symptoms at baseline.

CONCLUSIONS Practice audit and targeted education of general practitioners reduced the 2-year prevalence of depression and self-harm behavior by $10 \%$ compared with control physicians. The intervention had no effect on recovery from depression or self-harm behavior, but it prevented the onset of new cases of self-harm behavior during follow-up. Replication of these results is required before we can confidently recommend the roll-out of such a program into normal clinical practice.

Ann Fam Med 2012;10:347-356. doi:10.1370/afm.1368.

\section{BACKGROUND}

$\mathrm{D}$ epression is a common and disabling disorder that affects people of all ages ${ }^{1-4}$ and about $5 \%$ to $10 \%$ of adults older than 60 years. ${ }^{5,6}$ Recent attempts to reduce the prevalence of depression in the 
community have focused on improving the identification of people with depression ${ }^{7-11}$ and on increasing the efficacy of existing management strategies. ${ }^{12,13}$ Screening and case finding are the approaches most frequently used to identify people with depression in populations at risk, particularly in general practice settings. A metaanalysis of 16 randomized trials, however, found that the systematic use of screening instruments or case-finding procedures increased the recognition of depression by $27 \%$ but had no effect on the adoption of treatments or the outcome of patients. ${ }^{14}$

The evidence in support of the use of educational interventions targeting general practitioners to reduce the prevalence of depression and suicidal behavior remains inconclusive. Gilbody et $\mathrm{a}^{15}$ suggested that interventions incorporating clinician education, case management, and integration between primary and secondary care have a greater chance of being effective than interventions limited to education. ${ }^{16,17}$ For example, the Improving Mood-Promoting Access to Collaborative Treatment (IMPACT) trial recruited more than 1,800 older adults with major depression or dysthymia who were randomly assigned to usual care or an intervention that included supervised case management, education, support of antidepressant use, and brief problem solving therapy. ${ }^{18}$ After 12 months, $45 \%$ of patients in the intervention group had improved compared with only $19 \%$ of those receiving usual care $(\mathrm{OR}=3.4 ; 95 \% \mathrm{CI}, 2.7-4.4)$. A similar reduction in suicidal ideation was observed ${ }^{19}$ Other trials using collaborative care models to manage older adults with depression treated in primary care settings have reported similarly encouraging results, ${ }^{20-22}$ although gains were modest and the costs high. ${ }^{23,24}$ In addition, most published studies to date have had relatively small sample sizes and imprecise effect estimates, uncertain sustainability of the intervention in normal clinical practice, and inability to generalize these findings to the entire population of older adults reviewed in primary care.

The Depression and Early Prevention of Suicide in General Practice (DEPS-GP) trial was conceived to ascertain the effect of a simple and sustainable clinician-based education intervention and practice audit on the prevalence of depression and selfharm behavior in a large sample of primary care patients aged 60 years or older. Unlike previous trials, ${ }^{18,21}$ the DEPS-GP intervention targeted general practitioners and collected information on mental health outcomes from a nonselected group of their primary care patients. Our hypothesis was that older adults treated by the physicians in the intervention group would have a lower prevalence of a composite measure consisting of clinically significant depressive symptoms or self-harm behavior than the patients of control physicians.

\section{METHODS}

\section{Trial Design}

The DEPS-GP project was an open label, parallel, clustere-randomized trial with a 1-to-1 allocation ratio of general practitioners to a targeted and nontargeted educational intervention about depression and self-harm behavior. The Ethics Committees of the University of Western Australia, the University of Melbourne, and the Royal Australian College of General Practitioners approved the study protocol, and all participants provided informed consent. The study was conducted in accordance with the declaration of Helsinki and registered with the Australian New Zealand Clinical Trials Registry under the ACTR number 12605000049673 on July 25, 2005.

\section{Participants}

We posted a one-time invitation to take part in the study to 19,046 general practitioners listed on the Australasian Medical Publishing Company Proprietary Limited database and practicing in the Australian states of Western Australia, South Australia, Victoria, New South Wales, and Queensland. The accuracy and completeness of this list are unknown. There were 772 physicians who replied to our invitation, and 373 agreed to recruit adults aged 60 years or older for the study. Details about the recruitment process have been described elsewhere. ${ }^{25}$ We started recruitment in July 2005 and completed the collection of endpoints in June 2008.

\section{Intervention}

Participating physicians were the target of the intervention, which consisted of 3 components: (1) printed educational material about practical aspects of the assessment and management of depression and self-harm behavior in later life, (2) practice audit of 20 active patients with detailed personalized audit feedback that took place within the first 6 months of the study, and (3) newsletters outlining progress of the study. The newsletters were posted to participating physicians 6,12 , and 18 months after randomization.

Physicians participating in the educational activities of the project accrued points for the maintenance of professional standards.

Twenty consecutive patients aged 60 years or older attending the practice during the 4-week audit period were given a self-rating questionnaire by the receptionist at the time of their arrival at clinic. They were asked to record the date of the visit, their date of 
birth, sex, birthplace, marital status, and educational attainment, and to complete the 9-item Patient Health Questionnaire (PHQ-9) and the and the Depressive Symptom Index Suicidality Subscale (DSI-SS).

We used the PHQ-9 to assess depressive symptoms among the study patients. ${ }^{26}$ The PHQ-9 consists of 9 questions about how often the respondent has been bothered by depressive symptoms during the past 2 weeks, and each item can be scored 0 ("not at all"), 1 ("several days"), 2 ("a week or more") or 3 ("nearly every day"). A total score of 10 or more indicates the presence of clinically significant depression. ${ }^{27}$ The DSI-SS is a 4 -item self-report questionnaire designed to identify the frequency and intensity of suicidal ideation and impulses in the previous 2 weeks. Scores for each item of the DSI-SS range from 0 to 3, with higher scores reflecting greater severity of suicidal ideation. Past work has supported the scale's psychometric properties. ${ }^{28-30}$ Patients returned the questionnaires to the practice receptionist before their medical appointment.

After each of the 20 consultations reviewed during the audit period, each physician was asked to complete a 1-page summary sheet, which contained the following qustions: "Did you screen for mental health problems during this consultation? (yes/no)," "What is the likelihood that s/he was depressed? (high/ medium/low-none)," "Did you ask about suicide risk? (yes/no)," and "What was the suicide risk estimation? (high/medium/low-none)." We also asked the about the proposed management plan after the consultation: physician counseling (yes/no), referral to general hospital (yes/no), psychiatric hospital (yes/no), public mental health service (yes/no), private mental health service (yes/no), involvement of family or relevant others (yes/no), and prescription of antidepressant medication (yes/no), including the name of the antidepressant.

Physicians assigned to the educational intervention received detailed written audit feedback, which included a description of the number of patients with depression in their practice audit compared with other participating practices; the number of patients with depression and self-harm ideation (based on the PHQ algorithm developed by Spitzer and colleagues ${ }^{31}$ and a DSI-SS score of 1 or greater in any of the 4 screening items for self-harm) that they correctly identified compared with control physicians; the sex, date of birth, and specific symptoms of depression reported by each person with depression in their practice audit; and similar information for suicidal ideation. The also received educational material focused on the assessment and diagnosis of depression, identifying and managing suicidal risk in older adults, using antidepressant medication with this age-group, and crisis support contact information. Moreover, audit feedback directed physicians in the intervention group to relevant sections of the educational material. ${ }^{32}$

The newsletters posted to intervention physicians described the general information presented to the control group, as well as information about the signs and symptoms of depression most frequently found among older adults within the study, screening tips for uncovering depression and suicide risk, and case studies that provided cross-referencing to the educational material posted during the audit.

Physicians randomly assigned to the control group did not receive the printed education material, but they completed a practice audit and were mailed newsletters. In this case, audit feedback was limited to pooled data (ie, number of older adults with depression or suicidal ideation within their practice audit and across all participating physicians, and the proportion correctly identified within their practice and the study in general). Similarly, the newsletters posted to physicians in the control group were limited to general information about the number of physicians and older adults involved in the study, their demographic characteristics, and a snapshot of the interventions employed for treating depression.

\section{Outcomes}

The primary outcome of interest of this study was a composite measure of self-harm behavior or clinically significant depression (PHQ-9 $\geq 10$ ) recorded 12 or 24 months after recruitment.

We asked the study patients, "How often have you attempted suicide or intentionally harmed or injured yourself in the past year?" Possible answers were no, once, or more than once. We also asked them, "Have you thought about or attempted to kill yourself in the past year?" Possible answers were no or yes. We considered that self-harm behavior (ie, suicide ideation or attempt during the past year) was present in the past year if participants did not reply no to both questions.

\section{Other Measures}

Patients recorded the dates of assessment and birth, sex, place of birth, marital status, living arrangements, educational achievement, physical activity, smoking status, risky alcohol use, self-reported medical morbidities from a list of common morbidities, and history of physician diagnosis of depression. We used self-reported information on weight and height to calculate the body mass index $\left(\mathrm{kg} / \mathrm{m}^{2}\right)$, and the Duke Social Support Index as a measure of social support. ${ }^{33}$

We recorded information about the number of audits completed by participating physicians, self- 
reported use of antidepressants during the preceding 12 months, contact with mental health professionals, and support from family and friends to deal with health problems (nonspecified support) during the preceding 12 months. We retrieved medication data from the list of medications (prescription and nonprescription) provided by physicians at the 24-month assessment.

\section{Possible Factors Mediating the Effect of the Intervention on Outcomes}

We asked patients at the 12 and 24-month assessments whether they had received (1) antidepressant treatment during the preceding 12 months $_{i}$ (2) assessment or treatment from a psychiatrist, psychologist, or counselor in the preceding 12 months; and (3) any other form of support for health problems (including anxiety and depression) from non-health professionals (this last question was only asked at the 24-month assessment). In addition, we recorded the number of audits completed by each participating physician and considered that a minimum of 10 audits should have been completed (ie, $50 \%)$ to indicate compliance with the study protocol.

\section{Sample Size}

At trial registration, we had hoped to power the study to measure the effect of the intervention on suicide attempts over 2 years. As the number of consenting physicians was lower than the required 480 , we had to create a new primary outcome measure to achieve sufficient power. This new measure was a composite of clinically significant depressive symptoms (PHQ-9 $\geq 10$ ) or self-harm behavior. We calculated that we would need to recruit 21,600 older adults (or about 310 physicians; power $80 \%, \alpha=.05$ ). Assuming a loss to follow-up of about $15 \%$ to $20 \%$, we aimed to recruit 372 physicians into the study. We recruited 373 .

\section{Randomization}

The randomization procedure took place after the recruitment of physicians and their patients was finalized. Those who consented were randomly assigned to the intervention or control condition according to a list of random numbers generated by computer in blocks of 24 physicians, with equal numbers allocated to each study group. To decrease the risk of contamination, physicians working at the same practice received the same randomization number.

\section{Statistical Methods}

The data were managed and analyzed with Stata 11.1 (StataCorp). We used cross-tabulations to determine the distribution of covariates according to group assignment (Pearson's $\chi^{2}$ statistic).
We compared the proportion of patients in the intervention and control groups who met criteria for the primary composite outcome measure at either the 12- or the 24-month assessment; the same analysis was repeated separately for depressive symptoms and selfharm behavior. We used logistic regression (population average estimation) to examine the association between these outcomes and the intervention taking into account the baseline value of each outcome and relevant confounding variables.

We then stratified the analyses according to the presence or absence of depression or self-harm behavior at baseline. The data were organized with older adults at level 1 nested within practices/ physicians at level 2. Our initial analyses took into account the effect of clustering by practice and then by physician, but both were later dropped because their impact on the statistical models proved to be negligible (intraclass correlation coefficient $\leq 0.01$ ).

We applied imputation by chained equations to complete an intention-to-treat (ITT) analysis of the outcomes of interest (primary analysis). Older adults who died during follow-up were not included in the ITT analysis, as they could not possibly meet criteria for an endpoint of interest for the study. All variables available at baseline contributed information to calculate the missing values for the imputation files. We generated 5 imputed data sets to achieve stable estimates and $95 \%$ confidence intervals; $\alpha$ was set at .05 , and all statistical tests reported are 2 -tailed.

\section{RESULTS}

\section{Outcomes of Interest}

A total of 77,000 invitations, together with a replypaid envelope, were sent to all patients aged 60 years or older listed in these practices (average of 203 patients per physician): 42,384 did not respond, 9,087 patients declined to participate, 2,934 were returned as "not known at this address," $411 \mathrm{did}$ not meet the inclusion criteria (aged younger than 60 years or not reported), and 422 patients were excluded because of incomplete information on depressive symptoms and self-harm behavior, leaving a total study sample of 21,762 adults aged 60 years or older. Figure 1 shows the flow of study patients during the trial. The average number of patients recruited per participating physician was 58.5 (median $=44$, interquartile range $=21-82$, minimum-maximum $=1-300$ ).

The mean age of patients was 71.8 years (range $=60-101$ years), and those under the care of physicians in the intervention group were 0.5 years younger than those treated by physicians in the control group $(P<.001)$. There were more women than men in 
the sample $(58.8 \%)$, and a larger proportion were under the care of control physicians. Table 1 summarizes the demographic, lifestyle, and clinical characteristics of participating patients at the baseline assessment according to the allocation group of their physicians.

Older adults treated by physicians assigned to the intervention group were 10\% (95\% CI, 3\%-17\%) less likely than assigned to the control group to experience the composite primary outcome (ITT, Table 2). The effect of intervention on depression (PHQ-9 $\geq 10$ ) was not significant $(\mathrm{OR}=0.93 ; 95 \% \mathrm{CI}, 0.83-1.03)$, but its impact on suicide ideation/attempt over 24 months was significant $(\mathrm{OR}=0.80 ; 95 \% \mathrm{CI}, 0.68-0.94)$.

We then completed a series of post hoc analyses to clarify whether the intervention had a measurable effect on the onset of depression and self-harm behavior among those who were free of these symptoms at baseline (Table 3). Older adults treated by intervention physicians had lower odds of reporting self-harm behavior during follow-up than those treated by control physicians (adjusted $\mathrm{OR}=0.80 ; 95 \% \mathrm{CI}, 0.66-0.96$ ), although the effect was not significant for depressive symptoms (adjusted $\mathrm{OR}=0.90 ; 95 \% \mathrm{CI}, 0.79-1.03$ ). The intervention had no effect on 24-month recovery from depression or self-harm behavior in older adults who displayed these symptoms at baseline (Table 3).

\section{Secondary Analyses}

We investigated a number of factors that could have mediated the effect of the intervention on the outcomes of interest. Table 4 summarizes these results. A larger proportion of intervention compared with control physicians completed a minimum of 10 audits $(\mathrm{OR}=1.34$; 95\% CI, 1.25-1.43). Patients in the intervention group did not report greater use of antidepressant medications or contact with mental health professionals than older adults treated by control physicians. Likewise, there was no difference between the groups regarding the proportion of patients receiving other types of support (Table 4 ).

\section{DISCUSSION}

The results of this trial show that an educational intervention targeting general practitioners reduced the prevalence of a composite measure of clinically significant depression or self-harm behavior. The effect of the intervention was modest ( $3 \%$ to $17 \%$ reduction in the odds of having these symptoms at 24 months).

Our findings were derived from a clustered randomized trial that kept loss to follow-up during the 2 years within acceptable limits (15.6\% of patients) and recruited a sample size that was sufficiently large to detect small but meaningful clinical effects associated with the intervention. Although we used well-validated instruments and procedures to collect information about outcomes of interest, ${ }^{31}$ we acknowledge that our 
Table 1. Baseline Demographic, Lifestyle, and Clinical Characteristics of Older Adults, by General Practitioner Study Group

\begin{tabular}{|c|c|c|c|c|}
\hline Characteristic & $\begin{array}{c}\text { Control } \\
n=10,360 \\
n(\%)\end{array}$ & $\begin{array}{c}\text { Intervention } \\
n=11,402 \\
n(\%)\end{array}$ & $\chi^{2}$ (df) & $P$ Value \\
\hline Age-group, y & & & $32.58(5)$ & $<.001$ \\
\hline $60-64$ & $2,122(20.5)$ & $2,400(21.0)$ & & \\
\hline $65-69$ & $2,291(22.1)$ & $2,813(24.7)$ & & \\
\hline $70-74$ & $2,112(20.4)$ & $2,282(20.0)$ & & \\
\hline $75-79$ & $2,102(20.3)$ & $2,233(19.6)$ & & \\
\hline $80-84$ & $1,131(10.9)$ & $1,109(9.7)$ & & \\
\hline$\geq 85$ & $602(5.8)$ & $565(5.0)$ & & \\
\hline Female & $6,252(60.4)$ & $6,551(57.5)$ & $19.03(1)$ & $<.001$ \\
\hline Australian born & $7,573(73.5)$ & $8,511(75.0)$ & $6.55(1)$ & .010 \\
\hline \multicolumn{5}{|l|}{ Marital status } \\
\hline Married or de-facto & $6,652(64.5)$ & $7,786(68.7)$ & $41.77(1)$ & $<.001$ \\
\hline Living alone & $2,624(25.5)$ & $2,633(23.2)$ & $14.94(1)$ & $<.001$ \\
\hline Education, tertiary degree attained & $1,541(15.2)$ & $1,589(14.3)$ & $3.95(1)$ & .047 \\
\hline Physically active & $6,406(62.6)$ & $7,119(63.3)$ & $1.33(1)$ & .250 \\
\hline \multicolumn{5}{|l|}{ Smoking status } \\
\hline Never & $5,292(51.8)$ & $5,914(52.5)$ & $2.01(2)$ & .367 \\
\hline Past & $4,251(41.6)$ & $4,650(41.3)$ & - & - \\
\hline Current & $677(6.6)$ & $701(6.2)$ & - & - \\
\hline Risky alcohol use & $1,422(14.2)$ & $1,506(13.7)$ & $1.18(1)$ & .276 \\
\hline Overweight or obese (BMI >25) & $6,078(64.6)$ & $6,640(63.9)$ & $1.11(1)$ & .292 \\
\hline Social support index, lowest tertile & $7,584(73.9)$ & $8,402(74.3)$ & $0.63(1)$ & .428 \\
\hline \multicolumn{5}{|l|}{ Number of morbidities ${ }^{\mathrm{a}}$} \\
\hline 0 & $849(8.2)$ & $1,031(9.0)$ & $13.00(2)$ & .002 \\
\hline $1-5$ & $8,630(83.3)$ & $9,528(83.6)$ & - & - \\
\hline$\geq 6$ & $881(8.5)$ & $843(7.4)$ & - & - \\
\hline Past diagnosis of depression & $1,848(17.8)$ & $1,989(17.4)$ & $0.58(1)$ & .447 \\
\hline Current use of antidepressants & $1,344(13.0)$ & $1,386(12.2)$ & $3.30(1)$ & .069 \\
\hline
\end{tabular}

$\mathrm{BMI}=$ body mass index.

a Includes self-reported arthritis, diabetes, hypertension, stroke, coronary heart disease, congestive heart failure, peripheral arterial disease, asthma or chronic bronchitis, emphysema, osteoporosis, cancer (except skin cancer), dementia, thyroid disorders, and traumatic brain injury.

definition of depression was not based on a structured clinical interview, and that self-reported data about the 12-month diagnosis of depression and self-harm behavior were not externally validated. This type of error would not have biased the results of the trial (because error would have been randomly distributed), but it might have affected the measured effect-size of the intervention. In addition, because both groups of physicians participated in audit and feedback, which are activities that can change professional practice, ${ }^{37}$ we cannot dismiss a possible intervention effect in control physicians. As the process measures did not show any obvious change in the behavior of participating physicians regarding, for example, the prescription of antidepressants, it seems improbable that our results would have been affected in this way. Another limitation of our study design is that participating physicians were motivated volunteers rather than a random sample of practicing physicians, which creates some uncertainty as to whether the program would have been equally successful for the patients of physicians who chose not to participate in this trial. Because physicians with limited interest in mental health may benefit the most from this type of educational program, ${ }^{38}$ one would hope that the effect of the intervention would have been even greater in a nonselected sample of general practitioners.

We also acknowledge that our follow-up of patients was limited to 24 months, and it is unclear whether the modest effect of the intervention could have been sustained for a longer period. Furthermore, the patients of the 2 groups of physicians were not well balanced for some important variables associated with depression and self-harm behavior, such as age, sex, and living arrangements. We attempted to minimize the impact of such imbalance by forcing these variables into our statistical models, although residual error could have persisted and led to an inflation of our effect estimates.

Finally, we did not validate the self-reported information provided by participants regarding the number of consultations with their physicians and their use of health services during the 12 months leading up to the final assessment.

Previous studies investigating the effect of educational interventions that target general practitioners with the aim of reducing the prevalence of depression among their patients have produced mostly negative results. Data from the Hampshire Depression Project showed that, compared with control physicians, training to assess and manage depression did not improve detection or the outcome of patients with depression after 6 weeks and 6 months $(n=4,192) .{ }^{16} \mathrm{~A}$ similar Dutch study reported that the 3 -month outcome of 498 patients with depression treated by intervention general practitioners was better than the outcome of patients treated by control general practitioners, but the small differences between the groups were no 


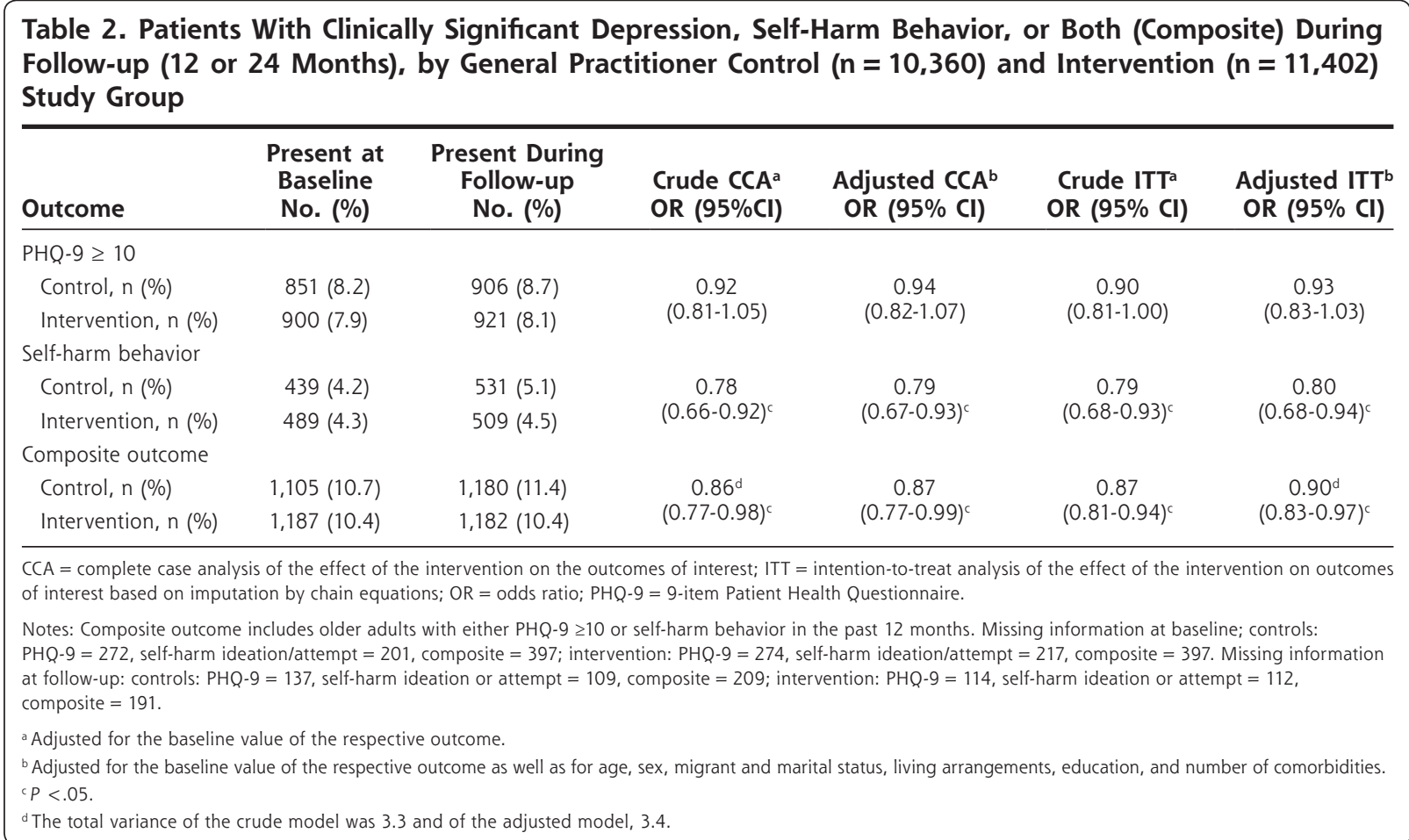

Table 3. Outcomes for Older Adults Treated by General Practitioners in Control and Intervention Groups, by Depression or Self-Harm Behavior at Study Entry

\begin{tabular}{|c|c|c|c|c|c|c|c|c|}
\hline \multirow[b]{2}{*}{ Outcome } & \multicolumn{2}{|c|}{12 Months } & \multicolumn{2}{|c|}{24 Months } & \multirow{2}{*}{$\begin{array}{c}\text { Crude CCA } \\
\text { OR } \\
(95 \% \mathrm{Cl})\end{array}$} & \multirow{2}{*}{$\begin{array}{c}\begin{array}{c}\text { Adjusted } \\
\text { CCA }^{a}\end{array} \\
\text { OR } \\
(95 \% \mathrm{Cl})\end{array}$} & \multirow{2}{*}{$\begin{array}{c}\text { Crude ITT } \\
\text { OR } \\
(95 \% \text { I) }\end{array}$} & \multirow{2}{*}{$\begin{array}{c}\text { Adjusted } \\
\text { ITTa }\end{array}$} \\
\hline & $\begin{array}{c}\text { Control } \\
\text { n (\%) }\end{array}$ & $\begin{array}{c}\text { Intervention } \\
\text { n (\%) }\end{array}$ & $\begin{array}{c}\text { Control } \\
\text { n (\%) }\end{array}$ & $\begin{array}{c}\text { Intervention } \\
\text { n (\%) }\end{array}$ & & & & \\
\hline \multicolumn{9}{|c|}{ Free of outcome at baseline assessment but displayed outcome at follow-up assessments (incident cases) } \\
\hline PHQ $-9 \geq 10$ & $210(2.3)$ & $212(2.1)$ & $500(5.4)$ & $505(4.9)$ & $\begin{array}{c}0.91 \\
(0.80-1.03)\end{array}$ & $\begin{array}{c}0.93 \\
(0.81-1.06)\end{array}$ & $\begin{array}{c}0.88 \\
(0.77-1.00)\end{array}$ & $\begin{array}{c}0.90 \\
(0.79-1.03)\end{array}$ \\
\hline $\begin{array}{l}\text { Self-harm } \\
\text { behavior }\end{array}$ & $187(1.9)$ & $163(1.5)$ & $335(3.4)$ & $283(2.6)$ & $\begin{array}{c}0.76 \\
(0.65-0.89)^{b}\end{array}$ & $\begin{array}{c}0.77 \\
(0.65-0.91)^{b}\end{array}$ & $\begin{array}{c}0.79 \\
(0.66-0.95)^{b}\end{array}$ & $\begin{array}{c}0.80 \\
(0.66-0.96)^{b}\end{array}$ \\
\hline $\begin{array}{l}\text { Composite } \\
\text { outcome }\end{array}$ & $290(3.3)$ & $272(2.8)$ & $629(7.1)$ & $599(6.1)$ & $\begin{array}{c}0.85 \\
(0.76-0.96)^{b}\end{array}$ & $\begin{array}{c}0.86 \\
(0.77-0.97)^{b}\end{array}$ & $\begin{array}{c}0.83 \\
(0.75-0.92)^{b}\end{array}$ & $\begin{array}{c}0.85 \\
(0.77-0.94)^{b}\end{array}$ \\
\hline \multicolumn{9}{|c|}{ Displayed outcome at baseline assessment but not at follow-up assessments (treatment response) } \\
\hline PHQ $-9<10$ & $225(26.4)$ & $273(30.3)$ & $336(39.5)$ & $394(43.8)$ & $\begin{array}{c}1.17 \\
(0.97-1.41)\end{array}$ & $\begin{array}{c}1.17 \\
(0.96-1.42)\end{array}$ & $\begin{array}{c}1.01 \\
(0.82-1.24)\end{array}$ & $\begin{array}{c}1.00 \\
(0.80-1.23)\end{array}$ \\
\hline $\begin{array}{l}\text { No self-harm } \\
\text { behavior }\end{array}$ & $147(33.5)$ & $153(31.3)$ & $228(51.9)$ & $239(48.9)$ & $\begin{array}{c}0.88 \\
(0.68-1.13)\end{array}$ & $\begin{array}{c}0.82 \\
(0.63-1.07)\end{array}$ & $\begin{array}{c}0.93 \\
(0.53-1.61)\end{array}$ & $\begin{array}{c}0.94 \\
(0.54-1.63)\end{array}$ \\
\hline $\begin{array}{l}\text { No composite } \\
\text { outcome }\end{array}$ & $293(26.5)$ & $338(28.5)$ & 440 (39.8) & $501(42.2)$ & $\begin{array}{c}1.06 \\
(0.90-1.25)\end{array}$ & $\begin{array}{c}1.03 \\
(0.87-1.22)\end{array}$ & $\begin{array}{c}1.09 \\
(0.92-1.30)\end{array}$ & $\begin{array}{c}1.08 \\
(0.90-1.29)\end{array}$ \\
\hline \multicolumn{9}{|c|}{$\begin{array}{l}C C A=\text { complete case analysis of the effect of the intervention on the outcomes of interest; ITT = intention-to-treat analysis of the effect of the intervention on the } \\
\text { outcomes of interest based on imputation by chain equations; OR = odds ratio; PHQ-9 = 9-item Patient Health Questionnaire. }\end{array}$} \\
\hline \multicolumn{9}{|c|}{$\begin{array}{l}\text { Note: The percentages displayed between brackets use the total number of participants in the relevant groups as the denominator, including missing cases. Composite } \\
\text { outcome includes older adults with either PHQ-9 } \geq 10 \text { or self-harm ideation/attempt in the past } 12 \text { months. }\end{array}$} \\
\hline
\end{tabular}

longer apparent after 12 months. ${ }^{17}$ These 2 studies focused on the outcome of primary care adult patients who were displaying clinically significant symptoms of depression, and their negative results are entirely consistent with our own. Together, these findings confirm that the depressed patients of general practitioners who participate in educational activities about depression do not have a better medium- to longterm outcome than the patients of general practitioners who do not take part in such activities. 


\begin{tabular}{|c|c|c|c|c|}
\hline Results & $\begin{array}{l}\text { Control } \\
\text { n (\%) }\end{array}$ & $\begin{array}{l}\text { Intervention } \\
\text { n (\%) }\end{array}$ & $\begin{array}{l}\text { Crude OR } \\
(95 \% \mathrm{Cl})\end{array}$ & $\begin{array}{l}\text { Adjusted } \\
\text { OR }^{\mathrm{a}} \\
(95 \% \mathrm{Cl})\end{array}$ \\
\hline \multicolumn{5}{|l|}{ All patients } \\
\hline Total, n & 10,360 & 11,402 & & \\
\hline Antidepressant use & $1,400(13.5)$ & $1,442(12.6)$ & $0.93(0.86-1.00)$ & $0.95(0.87-1.03)$ \\
\hline $\begin{array}{l}\text { Contact with mental } \\
\text { health professionals }\end{array}$ & $738(7.1)$ & $817(7.2)$ & $1.00(0.90-1.11)$ & $1.02(0.91-1.13)$ \\
\hline $\begin{array}{l}\text { Other nonspecified } \\
\text { support }\end{array}$ & $912(8.8)$ & $1,055(9.3)$ & $1.04(0.95-1.14)$ & $1.07(0.97-1.18)$ \\
\hline $\begin{array}{l}\text { Physician completed a } \\
\text { minimum of } 10 \text { audits }\end{array}$ & $8,106(78.2)$ & $9,440(82.8)$ & $1.34(1.25-1.43)^{b}$ & - \\
\hline \multicolumn{5}{|c|}{$\begin{array}{l}\text { Patients free of clinically significant symptoms of depression and suicide ideation } \\
\text { at baseline assessment who remained free of symptoms during follow-up }\end{array}$} \\
\hline Total, n & 7,375 & 8,281 & & \\
\hline Antidepressant use & $760(10.3)$ & $844(10.2)$ & $0.98(0.88-1.09)$ & $1.02(0.92-1.14)$ \\
\hline $\begin{array}{l}\text { Contact with mental } \\
\text { health professionals }\end{array}$ & $430(5.8)$ & $510(6.2)$ & $1.09(0.95-1.26)$ & $1.08(0.94-1.25)$ \\
\hline $\begin{array}{l}\text { Other nonspecified } \\
\text { support }\end{array}$ & $617(8.4)$ & $735(8.9)$ & $1.08(0.96-1.22)$ & $1.10(0.97-1.24)$ \\
\hline $\begin{array}{l}\text { Physician completed a } \\
\text { minimum of } 10 \text { audits }\end{array}$ & $6,067(82.3)$ & 7,171 (86.6) & $1.33(1.23-1.44)^{\mathrm{b}}$ & - \\
\hline \multicolumn{5}{|c|}{$\begin{array}{l}\text { Patients who displayed clinically significant symptoms of depression, suicide } \\
\text { ideation, or both at baseline but neither during follow-up }\end{array}$} \\
\hline Total, n & 440 & 501 & & \\
\hline Antidepressant use & $63(14.3)$ & $53(10.6)$ & $0.71(0.48-1.05)$ & $0.72(0.48-1.07)$ \\
\hline $\begin{array}{l}\text { Contact with mental } \\
\text { health professionals }\end{array}$ & $31(7.0)$ & $26(5.2)$ & $0.75(0.43-1.28)$ & $0.75(0.43-1.31)$ \\
\hline $\begin{array}{l}\text { Other nonspecified } \\
\text { support }\end{array}$ & $45(10.2)$ & $37(7.4)$ & $0.71(0.45-1.13)$ & $0.71(0.44-1.13)$ \\
\hline $\begin{array}{l}\text { Physician completed a } \\
\text { minimum of } 10 \text { audits }\end{array}$ & $352(80.0)$ & $410(81.8)$ & $1.13(0.81-1.56)$ & - \\
\hline \multicolumn{5}{|c|}{$\begin{array}{l}\text { Note: Percentages displayed use the total number of participants in the relevant groups as the denominator, } \\
\text { including missing cases. Information on the composite at baseline was missing for } 397 \text { and } 415 \text { older adults in } \\
\text { the control and intervention groups, respectively. The table also displays data on compliance with minimum audit } \\
\text { requirements of control and intervention physicians. }\end{array}$} \\
\hline \multicolumn{5}{|c|}{$\begin{array}{l}\text { a Adjusted for age, sex, migrant and marital status, living arrangements, education, and number of comorbidities. } \\
\mathrm{b} P<.05 \text {. }\end{array}$} \\
\hline
\end{tabular}

that these physicians were perceived as having greater understanding of patients' feelings and emotions. ${ }^{39}$ Interestingly, the study by Gask and colleagues ${ }^{39}$ also found that the patients of intervention general practitioners had better health perception and less role limitation caused by mental distress after 12 months than did the patients of control general practitioners, even though the groups showed no obvious difference on depression scores. These results suggest that education about depression and its treatment may improve the attitude of physicians toward mental health issues, which may lead to nonspecific better health outcomes for patients. The results of the Gotland educational program are consistent with such an interpretation.

In the early 1980s the Swedish Committee for Prevention and Treatment of Depression implemented an educational package about the diagnosis and treatment of depression for all general practitioners working on the island of Gotland. ${ }^{40}$ There is no published evidence that

We offered our intervention physicians education about screening, diagnosing, and managing depression as well as self-harm behavior. We found no evidence that participation in such activities decreased the prevalence of depression in a nonselected sample of patients, but we did find that older adults treated by intervention physicians were less likely to display self-harm behavior than their counterparts treated by control physicians. These results could not be adequately explained by more frequent use of antidepressants or contact with mental health professionals. It is possible that they were the product of chance (type I error), although other unmeasured factors could potentially explain these findings. For example, there is some evidence that patients of general practitioners randomly assigned to similar educational activities have a more positive view of their physicians, with at least one study showing the program reduced the prevalence of depression in Gotland, but the rates of completed suicide dropped dramatically during the subsequent 2 years: from 22 in 100,000 per year to 14.3 and 7.1 in 100,000 per year, respectively (the Gotland study was nonrandomized and without a contemporaneous control group). ${ }^{40}$ Because suicide behavior is closely associated with depression in later life, ${ }^{41,42}$ we had anticipated that changes in suicide ideation or behavior would be due to better treatment of depression in this population. Our results show that such is not the case and suggest that other factors (eg, a physician's empathy and willingness to discuss the emotional concerns of patients) may play a more important role than depression in reducing self-harm ideation in this agegroup. In fact, there is evidence that the relationship between patients and their primary care physicians 
has therapeutic value and, like social interventions, improves outcomes in a way that is different from formal treatments (such as medications). ${ }^{43,44}$

It is important to note that our intervention did not decrease the prevalence of depression or selfharm behavior. Instead, the prevalence of self-harm behavior increased slightly, but disproportionally, in control group patients, which seems to have been the main reason for the observed difference between the groups. It is unclear what might have caused these changes, but they were either due to unmeasured factors (eg, increased exposure to stress) ${ }^{45}$ or to the repeated questioning that allowed participants to feel progressively more comfortable to disclose their suicidal ideation. Another possibility is that asking about suicide intent increases the frequency of thoughts of self-harm, although existing data are not consistent with such interpretation. ${ }^{46}$ It is also possible that at study entry all participating physicians had a similar state of alertness to the need of screening and managing self-harm ideation, and that the activities of the project contributed to maintain or heighten such a state among intervention and control physicians during the follow-up period. Nonetheless, we concede that type I error could plausibly explain our findings, so that replication of these results is required before we can confidently recommend the roll out of such a program into normal clinical practice.

To read or post commentaries in response to this article, see it online at http://www.annfammed.org/content/10/4/347.

Key words: depression; suicide; education; aging; randomized trial; mental health: depression; health promotion; prevention

\footnotetext{
Author affiliations: School of Psychiatry \& Clinical Neurosciences, University of Western Australia, Perth, Australia (Almeida, Lautenschlager, Alfonso, Pfaff); Western Australian Centre for Health \& Ageing, Centre for Medical Research, University of Western Australia, Perth, Australia (Almeida, Flicker, Lautenschlager, Alfonso, Pfaff); Department of Psychiatry, Royal Perth Hospital, Perth, Australia (Almeida); School of Population Health, University of Melbourne, Melbourne, Australia (Pirkis); School of Population Health, University of Auckland, Auckland, New Zealand (Kerse); School of Medical Sciences, Edith Cowan University, Perth, Australia (Sim); School of Medicine and Pharmacology, University of Western Australia, Perth, Australia (Flicker); Department of Geriatric Medicine, Royal Perth Hospital, Perth, Australia (Flicker); Discipline of Psychiatry, Sydney Medical School, University of Sydney, Sydney, Australia (Snowdon); School of Psychiatry, University of New South Wales, New South Wales, Australia, (Draper); School of Medicine, University of Queensland, Queensland, Australia (Byrne); Department of Psychiatry, University of Adelaide, Adelaide, South Australia (Goldney); Academic Unit for Psychiatry of Old Age, St Vincent's Health, Department of Psychiatry, University of Melbourne, Melbourne, Australia (Lautenschlager); Discipline of General Practice, University of Adelaide, Adelaide, South Australia (Stocks).
}

Submitted June 16, 2011; submitted, revised, October 17, 2011; accepted November 2, 2011.
Funding support: The study was supported by the project grant number 353569 from the National Health and Medical Research Council of Australia (NHMRC) to Almeida, Pfaff, Kerse, Pirkis, Goldney, and Snowdon, and by an infrastructure grant from beyondblue Australia.

Disclaimer: The sponsors had no role in the design and conduct of the study; collection, management, analysis, and interpretation of the data; or preparation, review, or approval of the manuscript.

Acknowledgments: The investigators thank participants and research staff for their generous contributions.

\section{References}

1. Kessler RC, Berglund P, Demler O, et al; National Comorbidity Survey Replication. The epidemiology of major depressive disorder: results from the National Comorbidity Survey Replication (NCS-R). JAMA. 2003:289(23):3095-3105.

2. Prince $M$, Patel V, Saxena $S$, et al. No health without mental health. Lancet. 2007;370(9590):859-877.

3. Penninx BW, Geerlings SW, Deeg DJ, van Eijk JT, van Tilburg W, Beekman AT. Minor and major depression and the risk of death in older persons. Arch Gen Psychiatry. 1999;56(10):889-895.

4. Alexopoulos GS, Bruce ML, Hull J, Sirey JA, Kakuma T. Clinical determinants of suicidal ideation and behavior in geriatric depression. Arch Gen Psychiatry. 1999;56(11):1048-1053.

5. Byers AL, Yaffe K, Covinsky KE, Friedman MB, Bruce ML. High occurrence of mood and anxiety disorders among older adults: The National Comorbidity Survey Replication. Arch Gen Psychiatry. 2010;67(5):489-496.

6. Pirkis J, Pfaff J, Williamson $M$, et al. The community prevalence of depression in older Australians. J Affect Disord. 2009;115(1-2):54-61.

7. Kessler D, Lloyd K, Lewis G, Gray DP. Cross sectional study of symptom attribution and recognition of depression and anxiety in primary care. BMJ. 1999;318(7181):436-439.

8. Pfaff JJ, Almeida OP. A cross-sectional analysis of factors that influence the detection of depression in older primary care patients. Aust N Z J Psychiatry. 2005;39(4):262-265.

9. Arroll B, Elley CR, Fishman T, et al. Antidepressants versus placebo for depression in primary care. Cochrane Database Syst Rev. 2009; 8(3):CD007954

10. Rush AJ, Trivedi MH, Wisniewski SR, et al. Acute and longer-term outcomes in depressed outpatients requiring one or several treatment steps: a STAR*D report. Am J Psychiatry. 2006;163(11):1905-1917.

11. Fournier JC, DeRubeis RJ, Hollon SD, et al. Antidepressant drug effects and depression severity: a patient-level meta-analysis. JAMA. 2010;303(1):47-53.

12. Kirsch I, Deacon BJ, Huedo-Medina TB, Scoboria A, Moore TJ, Johnson BT. Initial severity and antidepressant benefits: a meta-analysis of data submitted to the Food and Drug Administration. PLoS Med. 2008;5(2):e45.

13. Corey-Lisle PK, Nash R, Stang P, Swindle R. Response, partial response, and nonresponse in primary care treatment of depression. Arch Intern Med. 2004;164(11):1197-1204.

14. Gilbody S, Sheldon T, House A. Screening and case-finding instruments for depression: a meta-analysis. CMAJ. 2008;178(8):997-1003.

15. Gilbody S, Whitty P, Grimshaw J, Thomas R. Educational and organizational interventions to improve the management of depression in primary care: a systematic review. JAMA. 2003;289(23):3145-3151.

16. Thompson C, Kinmonth AL, Stevens L, et al. Effects of a clinicalpractice guideline and practice-based education on detection and outcome of depression in primary care: Hampshire Depression Project randomised controlled trial. Lancet. 2000;355(9199):185-191. 
17. Tiemens BG, Ormel J, Jenner JA, et al. Training primary-care physicians to recognize, diagnose and manage depression: does it improve patient outcomes? Psychol Med. 1999;29(4):833-845.

18. Unützer J, Katon W, Callahan CM, et al; IMPACT Investigators. Improving Mood-Promoting Access to Collaborative Treatment. Collaborative care management of late-life depression in the primary care setting: a randomized controlled trial. JAMA. 2002;288(22) 2836-2845.

19. Unützer J, Tang L, Oishi S, et al; for the IMPACT Investigators. Reducing suicidal ideation in depressed older primary care patients. J Am Geriatr Soc. 2006;54(10):1550-1556.

20. Bruce ML, Ten Have TR, Reynolds CF III, et al. Reducing suicidal ideation and depressive symptoms in depressed older primary care patients: a randomized controlled trial. JAMA. 2004;291(9):1081-1091.

21. van't Veer-Tazelaar PJ, van Marwijk HW, van Oppen P, et al. Stepped-care prevention of anxiety and depression in late life: a ran domized controlled trial. Arch Gen Psychiatry. 2009;66(3):297-304.

22. van't Veer-Tazelaar PJ, van Marwijk HW, van Oppen P, et al. Prevention of late-life anxiety and depression has sustained effects over 24 months: a pragmatic randomized trial. Am J Geriatr Psychiatry. 2011;19(3):230-239.

23. Schoenbaum M, Unützer J, Sherbourne C, et al. Cost-effectiveness of practice-initiated quality improvement for depression: results of a randomized controlled trial. JAMA. 2001;286(11):1325-1330.

24. Gilbody S, Bower P, Whitty P. Costs and consequences of enhanced primary care for depression: systematic review of randomised economic evaluations. Br J Psychiatry. 2006;189:297-308.

25. Williamson MK, Pirkis J, Pfaff JJ, et al. Recruiting and retaining GPS and patients in intervention studies: the DEPS-GP project as a case study. BMC Med Res Methodol. 2007;Sep 18;7:42.

26. Kroenke K, Spitzer RL, Williams JB. The PHQ-9: validity of a brief depression severity measure. J Gen Intern Med. 2001;16(9):606-613.

27. Arroll B, Goodyear-Smith F, Crengle S, et al. Validation of $\mathrm{PHQ}-2$ and $\mathrm{PHQ}-9$ to screen for major depression in the primary care population. Ann Fam Med. 2010;8(4):348-353.

28. Joiner TE Jr, Pfaff JJ, Acres JG. A brief screening tool for suicidal symptoms in adolescents and young adults in general health settings: reliability and validity data from the Australian National General Practice Youth Suicide Prevention Project. Behav Res Ther. 2002;40(4):471-481.

29. Joiner TE Jr, Rudd MD. Negative attributional style for interpersonal events and the occurrence of severe interpersonal disruptions as predictors of self-reported suicidal ideation. Suicide Life Threat Behav. 1995;25(2):297-304

30. Joiner TE Jr, Rudd MD. Disentangling the interrelations between hopelessness, loneliness, and suicidal ideation. Suicide Life Threat Behav. 1996;26(1):19-26.

31. Spitzer RL, Kroenke K, Williams JB. Validation and utility of a selfreport version of PRIME-MD: the PHQ primary care study. Primary Care Evaluation of Mental Disorders. Patient Health Questionnaire. JAMA. 1999;282(18):1737-1744.
32. Pfaff J, Almeida OP. Identifying and Managing Suicidal Risk in Older Adults: A Desktop Reference Guide for General Practice. Perth: Advance Press; 2003.

33. Koenig HG, Westlund RE, George LK, Hughes DC, Blazer DG, Hybels C. Abbreviating the Duke Social Support Index for use in chronically ill elderly individuals. Psychosomatics. 1993;34(1):61-69.

34. Pfaff JJ, Almeida OP. Detecting suicidal ideation in older patients: identifying risk factors within the general practice setting. $\mathrm{Br} J \mathrm{Gen}$ Pract. 2005;55(513):269-273.

35. O'Connor DW, Rosewarne R, Bruce A. Depression in primary care. 2: general practitioners' recognition of major depression in elderly patients. Int Psychogeriatr. 2001;13(3):367-374.

36. Arroll B, Macgillivray S, Ogston S, et al. Efficacy and tolerability of tricyclic antidepressants and SSRIs compared with placebo for treatment of depression in primary care: a meta-analysis. Ann Fam Med. 2005;3(5):449-456

37. Jamtvedt G, Young JM, Kristoffersen DT, O'Brien MA, Oxman AD. Audit and feedback: effects on professional practice and health care outcomes. Cochrane Database Syst Rev. 2006;19:2:CD000259.

38. Richards JC, Ryan P, McCabe MP, Groom G, Hickie IB. Barriers to the effective management of depression in general practice. Aust $N$ Z J Psychiatry. 2004;38(10):795-803

39. Gask L, Dowrick C, Dixon C, et al. A pragmatic cluster randomized controlled trial of an educational intervention for GPs in the assessment and management of depression. Psychol Med. 2004;34(1):63-72.

40. Rutz W, von Knorring L, Wålinder J. Frequency of suicide on Gotland after systematic postgraduate education of general practitioners. Acta Psychiatr Scand. 1989;80(2):151-154

41. Lawrence D, Almeida OP, Hulse GK, Jablensky AV, Holman CD. Suicide and attempted suicide among older adults in Western Australia. Psychol Med. 2000;30(4):813-821.

42. Conwell Y, Duberstein PR, Cox C, Herrmann JH, Forbes NT, Caine ED. Relationships of age and axis I diagnoses in victims of completed suicide: a psychological autopsy study. Am J Psychiatry. 1996;153(8):1001-1008.

43. Gater R, Waheed W, Husain N, Tomenson B, Aseem S, Creed F. Social intervention for British Pakistani women with depression: randomised controlled trial. Br J Psychiatry. 2010;197(3):227-233.

44. Palmer V, Gunn J, Kokanovic R, et al. Diverse voices, simple desires: a conceptual design for primary care to respond to depression and related disorders. Fam Pract. 2010;27(4):447-458.

45. Fairweather AK, Anstey KJ, Rodgers B, Jorm AF, Christensen $H$. Age and gender differences among Australian suicide ideators: prevalence and correlates. J Nerv Ment Dis. 2007;195(2):130-136.

46. Crawford MJ, Thana L, Methuen C, et al. Impact of screening for risk of suicide: randomised controlled trial. Br J Psychiatry. 2011; 198(5):379-384 